\title{
Comparative Analysis of GPON and DSL Access Technologies for Enhancing Broadband Internet Penetration in Nigeria
}

\author{
Agboje Oboyerulu Edevbie \\ Department of Electrical and Information \\ Engineering \\ Covenant University, Nigeria
}

\author{
Olowononi Felix Opeyemi \\ Department of Electrical and Information \\ Engineering \\ Covenant University, Nigeria
}

\begin{abstract}
Broadband penetration is a core driver of the economic development of any nation. The broadband supply chain comprises of international connectivity, a national backbone network, metropolitan access links and the local access (or last mile) network. In Africa, so much activity has been recorded with regards to international connectivity with a lot of investment from various consortia. Nigeria recently joined the nations with a National Broadband Plan in 2012, however, to meet the goal of the Nigerian National Broadband Plan of increasing broadband penetration from $6 \%$ in 2013 to $30 \%$ in 2018 , it must leverage on developments in the technology of the access network. The access platform for broadband services has evolved over the years from the use of Very Small Aperture Terminals, Asynchronous Transfer Mode (ATM) and Digital Subscriber Line (DSL) to optical access systems. Optical access transmission systems have the capacities for almost unlimited increases in speed and have become the ultimate technologies for broadband access. The access network is of prime importance due to its proximity to the major personnel in the broadband ecosystem; the consumer or subscriber. Deployment of broadband services to the end user can be achieved via Wired (GPON, ADSL, DSL...) or Wireless technologies (EDGE, UMTS, HSPA, LTE). The present access technology hinges on mobile wireless technologies (EDGE and $3 \mathrm{G}$ ) with complementary efforts by DSL. This paper is therefore set to present a comparative analysis of Passive Optical Networks (majorly Gigabit Passive Optical Network) and DSL access technologies for enhancing broadband internet penetration in Nigeria.
\end{abstract}

\section{Keywords}

DSLAM, FTTx, GPON, LTE, OLT, ONU, xDSL

\section{INTRODUCTION}

Advancements in various fields of engineering and technology such as the convergence of voice, video and data, enhanced modulation and multiplexing schemes, advancements in integrated circuit and nanotechnology among others has resulted in a corresponding development of services such as online gaming, internet banking, ecommerce, e-shopping, e-learning, video conferencing and many social media applications like Skype, Facebook, Twitter and Instagram. Other factors responsible for the growth in the Internet and the future of Internet of Things (IoT) include the availability of smart phones with internet connectivity, the drop in the cost of Wi-Fi bandwidth and computing resources by about 40 times and 60 times respectively over the last 10 years on average, the dramatic reduction in the cost of sensors over the last 10 years (from $\$ 1.30$ to $\$ 0.60$ ) on average and finally the launch of the IPv6 with its ability to address $3.4 \mathrm{x}$ $10^{38}$ unique IP addresses [1].

Consequently, the narrowband internet services are not able to cope with the 'bandwidth-hungry' applications hence the need for deployment of broadband internet technology. Presently, the internet and broadband have been globally acknowledged as the foundation for transformation to a knowledge-based economy. Broadband infrastructure has also been recognized as an enabler for economic and social growth in the digital economy [2]. Furthermore, empirical proof by the World Bank has ascertained that a $10 \%$ increase in broadband penetration in developing countries guarantees a corresponding increase in GDP by $1.3 \%$ [3].

A communication system usually consists of three parts namely the core, the backhaul and the access. In telecommunications, the network core refers to the central part of a telecommunications network that provides various services to customers who are connected by the access network. The backhaul of the network is the link or network infrastructure between the core of the network and the access, responsible for transporting communication data from end users or nodes to the central network or infrastructure and vice versa.

The deployment of broadband technology in Nigeria has been hampered due to the lack of adequate infrastructure for access by the end user and customers. The access network is of prime importance due to its proximity to the major personnel in the broadband ecosystem; the consumer or subscriber. Deployment of broadband services to the end user can be achieved via Wired (GPON, ADSL, DSL...) or Wireless technologies (EDGE, UMTS, HSPA, LTE). The major technology used in Nigeria is the mobile wireless technology and is evident in the fact that the number of Base Transceiver Stations (BTS) built by telecommunication companies increased from 28,000 in early 2014 to about 30,000 at the end of 2014 [4]. The government of the nation has recognized the importance of Internet penetration and in 2012, the Presidential committee for a national broadband and roadmap was inaugurated and their efforts originated in the development of the Nigeria's National Broadband Plan: 2013 - 2018. The major highlight of the national broadband plan is to leapfrog broadband intent penetration from $6 \%$ in 2013 to $30 \%$ in 2018 [2]. This goal cannot be achieved without placing the searchlight on the access technologies and attempting to leverage on the developments therein. One of the access technologies that caused a lot of stir when proposed is the Broadband over Power Line (BPL) technology. This 
technology that involves the transmission of information over conductors used for electric power transmission was quickly dismissed in Nigeria due to the poor state of power in the nation. Nevertheless, it generated a lot of attraction from national governments of advanced nations, the European Union (EU) and the Organization for Economic Cooperation and Deployment (OECD) given its apparent ease of deployment and negligible environmental impact. After numerous global trials in the last few years, telecommunication companies and Internet Service Providers (ISPs) have not succeeded in achieving the desired reach and bandwidth to make it a viable option for other competitive solutions like ADSL, Wi-Fi and 3G mobile broadband services which are constantly evolving in speed and reach [5].

Optical communication technology is engendering a worldwide revolution in the telecommunication industry due to its capacity for almost unlimited increases in speed and hence, has become the ultimate technology for broadband access. Passive Optical Networks are always evolving and possess a great potential for accelerating broadband internet penetration relatively to the variants of the Digital Subscriber Line currently serving as a complement to the wireless access technologies. As Nigeria and other developing nations seek to leverage on the opportunities and potentials of the broadband internet deployment, models that optimize the developments in the broadband access technology must be developed and implemented.

\section{OVERVIEW OF BROADBAND DEPLOYMENT IN NIGERIA}

The demand for fast, reliable and affordable internet access has accelerated in recent years but prior to this moment; there have been a lot of developments in the telecommunications industry. Notable among these developments was the commercialization of the government owned NITEL and the establishment of the Nigeria Communications Commission (NCC) as the telecommunications industry regulator in 1992. The result of the establishment of the NCC was the release of the National Telecommunication Policy in September 2000 and subsequently the auctioning of $2 \mathrm{G}$ digital mobile licenses to various investors in 2001 and 2002. The figure below illustrates the progression of the mobile market share in 2002 to $2004[6,7]$.

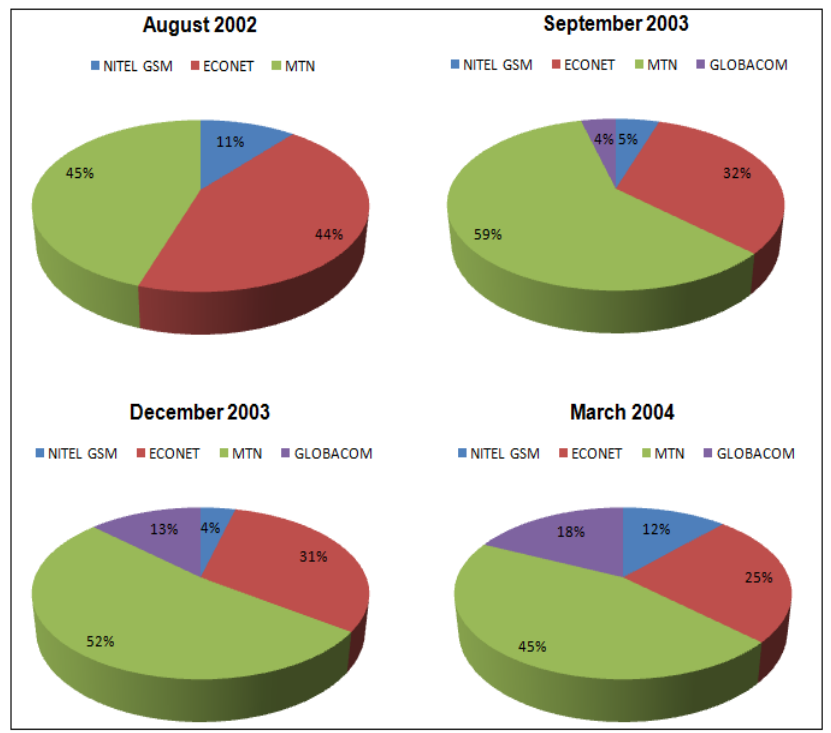

Figure 1: Selective Mobile market share in 2002 - 2004 [7]

As a result of this, the telecommunication sector underwent a rapid change and experienced explosive growth between the year 2002 and 2004. Subsequently, the total subscriber base for connected fixed and mobile lines rose at an average growth of $125 \%$ annually.

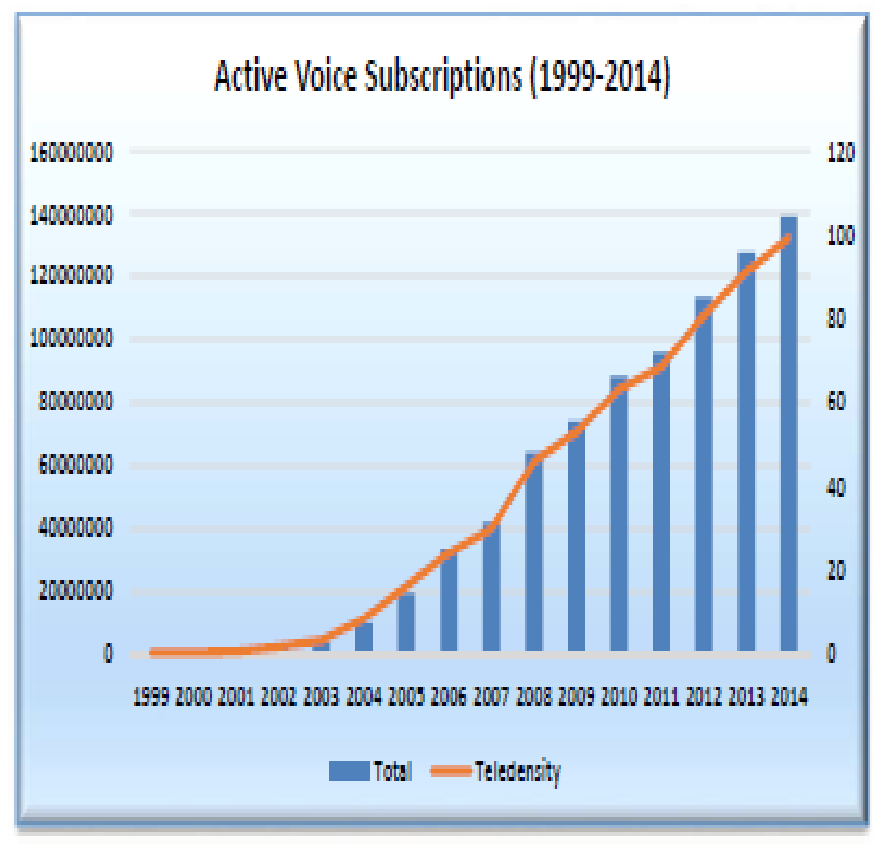

Figure 2: Trend of Active Voice Subscriptions /Teledensity data (1999 - 2014) [4]

All around the world, many consortia and government ministries have invested hugely in the laying of undersea long-haul fiber optic cables and presently, submarine data cables handle more than $95 \%$ of IP voice and data traffic between countries and continents and $100 \%$ of international internet traffic. According to a comprehensive market research report by Global Industry Analysts, cumulative global installation of submarine optical fiber cable is expected 
to reach two million kilometers by 2018 , up from just over one million kilometers in 2009 [8,9]. Nigeria has not been left out of this global trend as it currently boasts of four cables with landing points in it. This development which began in 2010 has been a major contribution to the growth of broadband internet penetration in Nigeria and was birthed in response to the need to connect Africa to the other parts of the world. From 4.7 Terabytes in 2010, the entry of GLO-1, MainOne, WACS and ACE has bolstered the data throughput to 11 Terabytes [2]. It is pertinent to state that prior to this period, NITEL owned SAT-3 cable was the major submarine fiber optic cable providing bandwidth to the Nigerian economy with international connectivity.

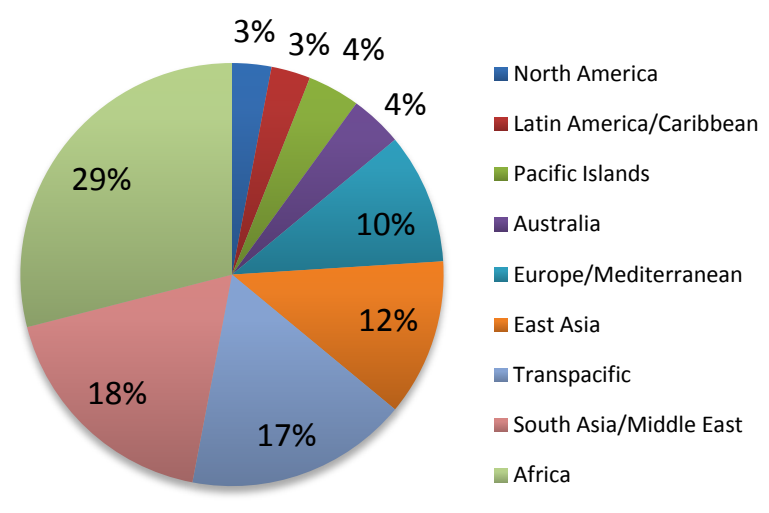

Figure 3: Investment in New Submarine Fiber Optic Projects by Region: 2008 - 2012 [10]

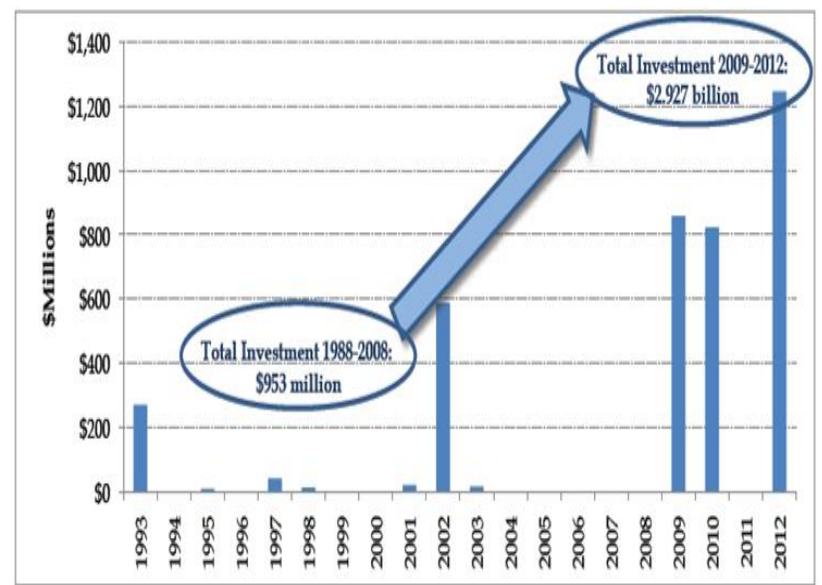

Figure 4: Investment in New Sub-Saharan African Systems: 1993 - 2012 [10]

It is however unfortunate that up till date, only about $10 \%$ of the total capacity of undersea cables in Nigeria is currently being utilized. Consequently, the effort of all the investors has resulted in only about $6 \%$ in internet penetration due to reliance on wireless access technologies. There is therefore no doubt that the broadband access network has to be revisited and modern technologies leveraged on to guarantee that the aim of the national broadband plan is considerably fulfilled.

\section{BROADBAND ACCESS NETWORKS: AN OVERVIEW}

Network infrastructure plays a key role in the success of added services and consequently in the user satisfaction. Access networks are also commonly referred to as either 'the last mile' by the operators, or the 'first mile of the network' in IEEE terminology. The term 'mile' is often related to the path portion that is used to reach the user from a network node, however access networks go as far as $20 \mathrm{Km}$ depending on the technology used. In essence, an access network comprises connections between different subscribers and a Central Office $(\mathrm{CO})$, which is attached to the metro or core network.

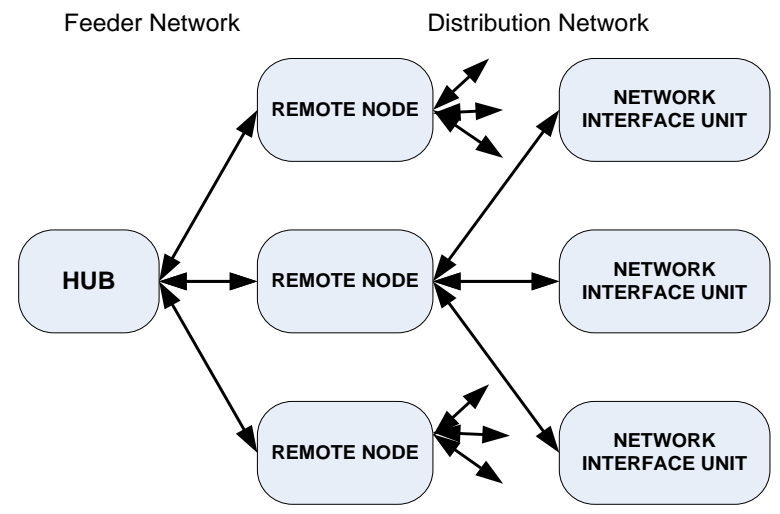

Figure 5: Architecture of an Access Network

There is a strong competition for broadband access services between several technologies namely Digital Subscriber Loop, coaxial cable, wireless and FTTx (fiber to the $\mathrm{x}$, where $\mathrm{x}$ stands for home, curb, neighborhood, office, business, premise, user, etc). Due to the capital cost of deploying each of these access technologies, the business concerns are very paramount hence, to survive competition, the inventors or operators of each of these technologies are constantly researching on newer methodologies to increase the bandwidth/user and reach of each of these technologies. This therefore results in newer versions and variants of these access technologies. According to information gathered by Leonid Kazovsky in 2007 and presented in the table below is a list showing the bandwidth and reach capabilities of the competing technologies.

Table 1: Bandwidth/User and Max Reach of Various Access Technologies[11]

\begin{tabular}{|c|c|c|}
\hline SERVICE & BANDWIDTH/USER & $\begin{array}{c}\text { MAXIMUM } \\
\text { REACH }\end{array}$ \\
\hline ADSL & $2 \mathrm{Mb} / \mathrm{s}$ (typical) & $5.5 \mathrm{~km}$ \\
\hline VDSL & $20 \mathrm{Mb} / \mathrm{s}$ (typical) & $1 \mathrm{~km}$ \\
\hline Coaxial & $2 \mathrm{Mb} / \mathrm{s}$ (typical)* & $0.5 \mathrm{~km}$ \\
\hline Wi-Fi & $54 \mathrm{Mb} / \mathrm{s}$ (typical) & $0.1 \mathrm{~km}$ \\
\hline WiMax & $28 \mathrm{Mb} / \mathrm{s}$ (typical) & $15 \mathrm{~km}$ \\
\hline
\end{tabular}




\begin{tabular}{|c|c|c|}
\hline BPON & $20 \mathrm{Mb} / \mathrm{s}$ (typical)* & $20 \mathrm{~km}$ \\
\hline EPON & $60 \mathrm{Mb} / \mathrm{s}$ (typical)* & $20 \mathrm{~km}$ \\
\hline GPON & $40 \mathrm{Mb} / \mathrm{s}$ (typical)* & $20 \mathrm{~km}$ \\
\hline
\end{tabular}

*bandwidth depends on the number of users

However, due to advances in photonics technologies and a worldwide deployment of optical fibers, core transport networks have experienced an extraordinary increase in transmission capacity during the last decade.

\subsection{The Digital Subscriber Line Technology}

Digital subscriber line (DSL) is a broadband access technology with the telephone-grade copper pair as the transmission medium. It was originally defined for the transport of analog voice with a maximum frequency of 3.4 $\mathrm{kHz}$ [16]. The modulation scheme employed in this technology is the highly effective Discrete Multitone (DMT) modulation with a performance close to the theoretical limit given by the Shannon theorem. There are different types or variants of the DSL technology based on the highest frequencies used on the medium; these include ADSL, ADSL2, ADSL2+, VDSL and VDSL2. The maximum achievable aggregate bit rate for upstream and downstream traffic is roughly proportional to the number of carriers employed, and thus to the overall bandwidth used on the medium, if interference is neglected. Carriers are grouped in bands for upstream and downstream transmission and much more spectrum is allocated to downstream traffic, thereby making most DSL implementations highly asymmetric [16]. As the population of users of this system increased, the need to interconnect multiple DSL users to a high-speed backbone network led to the development of the Digital Subscriber Line Access Multiplexer (DSLAM). The DSLAM operated by connecting to an asynchronous transfer mode (ATM) network with aggregate data transmission capacity in the gigabit order. At the other end of each transmission, a DSLAM demultiplexes the signals and forwards them to appropriate individual DSL connections.

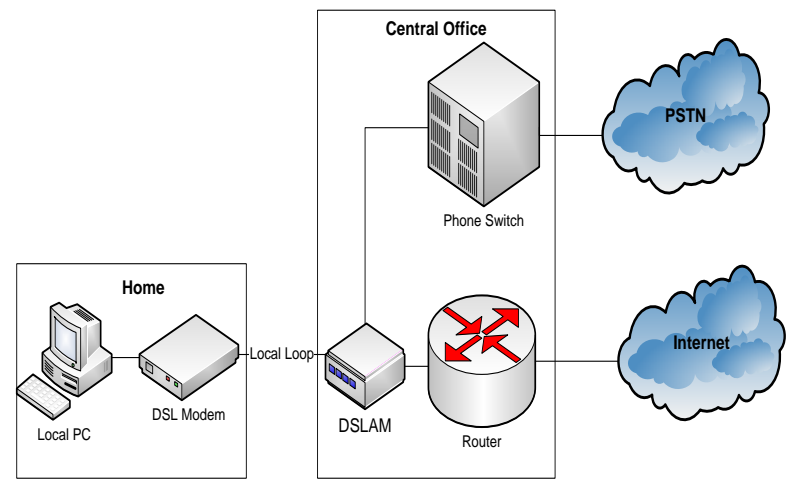

Figure 6: Architecture of a typical DSL access network

Similar to other wired transmission media, attenuation and crosstalk are two major limitations to the use of DSL technology. While attenuation grows exponentially with the length of the medium, and logarithmically with the frequency; Crosstalk is majorly a function of the frequency, power of the signal, and the number of active pairs in a cable. Since the Signal-to-Noise Ratio (SNR) decreases with increasing attenuation and increasing noise from crosstalk; and higher bit rates require higher frequencies, which in turn increase attenuation and crosstalk, high bit rates can only be achieved only over short distances. DSL is therefore clearly more limited in capacity and distance than all-fiber approaches

\subsection{The Passive Optical Network}

The bandwidth demand in the access network has been increasing rapidly over the past several years. While residential subscribers demand last-mile solutions that offer high bandwidth and media-rich services, corporate users demand broadband infrastructure through which they can connect their LANs to the internet backbone.

The Passive Optical Network is an optical fiber based network architecture which can provide much higher bandwidth in the access network compared to traditional copper-based networks. A PON is a point-to-multipoint optical network where an optical line terminal (OLT) at the Central Office (CO) is connected to many Optical Network Units (ONU) at remote nodes through one or more multiple $1: \mathrm{N}$ optical splitters. The network between the OLT and ONU is passive i.e. it does not require any power supply.

\section{Passive Optical Network}

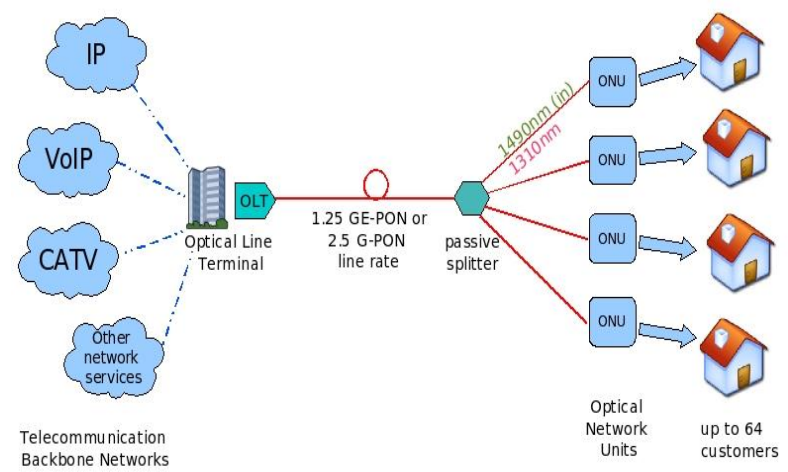

Figure 7: Architecture of the Passive Optical Network

Passive Optical Networks have evolved over the years from ATM PON (APON) to Broadband PON (BPON), Ethernet PON (EPON and newer GePON) and then Gigabit PON (GPON). GPON can transport not only Ethernet, but ATM and TDM (including PSTN, ISDN, E1 and E3) traffic by using GPON encapsulating method (GEM) [12]. GPONs typically provide distributed connectivity over a large geographic area. Furthermore, a typical GPON model employs a tree-like topology consisting of one OLT, ONT/ONU and splitter/Optical Distribution Network. The table below gives the major characteristics of the GPON vs. EPON to further depict the evolution.

Table 2: GPON vs EPON [13]

\begin{tabular}{|l|l|l|}
\hline & GPON & EPON \\
\hline $\begin{array}{l}\text { Standard } \\
\text { Organization }\end{array}$ & ITU-T & IEEE \\
\hline Rate & $2.488 \mathrm{G} / 1.244 \mathrm{G}$ & $1.25 \mathrm{G} / 1.25 \mathrm{G}$ \\
\hline Split Ratio & $1: 64-1: 128$ & $1: 16-1: 128$ \\
\hline Carried Service & $\begin{array}{l}\text { ATM, Ethernet, } \\
\text { TDM }\end{array}$ & ETHERNET \\
\hline $\begin{array}{l}\text { Bandwidth } \\
\text { Efficiency }\end{array}$ & $92 \%$ & $72 \%$ \\
\hline Quality of Service & Very Good & Good \\
\hline
\end{tabular}




\begin{tabular}{|l|l|l|}
\hline (QoS) & $\begin{array}{l}\text { Including Ethernet, } \\
\text { TDM, ATM }\end{array}$ & \\
\hline Optical Budget & CLASS A/B/B+/C & Px10/Px20 \\
\hline $\begin{array}{l}\text { Dynamic } \\
\text { Bandwidth } \\
\text { Allocation (DBA) }\end{array}$ & Standard Format & Self defined \\
\hline $\begin{array}{l}\text { Communication } \\
\text { with ONTs }\end{array}$ & $\begin{array}{l}\text { ONT Management } \\
\text { Control Interface }\end{array}$ & Not Supported \\
\hline $\begin{array}{l}\text { Operation and } \\
\text { Maintenance }\end{array}$ & $\begin{array}{l}\text { ITU-T G.984 } \\
\text { (Strong) }\end{array}$ & $\begin{array}{l}\text { Ethernet OAM } \\
\text { (Weak) }\end{array}$ \\
\hline
\end{tabular}

\section{COMPARATIVE ANALYSIS OF GPON AND XDSL}

The fact that wired access technologies have more advantages over wireless access technologies is already established. However, Nigeria as a nation is still highly dependent on wireless access technologies despite the challenges of this medium. Here, comparison is made between DSL and GPON technologies from the perspective of fast tracking broadband internet penetration in the nation.

\subsection{The Speed Factor}

Despite the fact that Digital Subscriber Line (DSL) has been evolving in the past years to accommodate higher speeds, its speed cannot still be compared to that obtainable by the evolution of Passive Optical Networks (PON) technologies. The bandwidth speed obtainable over any DSL infrastructure resides between a several hundred kilobits per second to a few megabits per second. GPON as the name implies has already crossed the gigabit range and more developments are expected in the future as research progresses. The figure below shows the evolution in throughput capacity of both technologies over the years. To be able to sustain the developments of applications that are constantly evolving, there is a need to leverage on the better throughput capability of the GPON system.

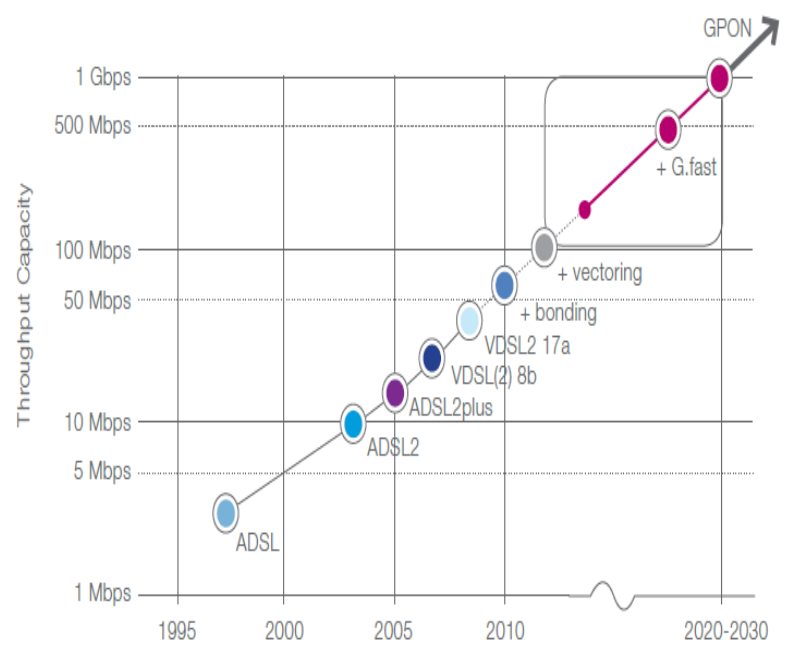

Figure 8: Evolution of access technologies in speed over the years [14]

\subsection{The Reach Factor}

Two of the major desired qualities of any access technology are that of its bandwidth speed and the range of coverage otherwise referred to as its reach. DSL is however affected by two kinds of impairments namely attenuation and crosstalk. Since attenuation grows exponentially with the length of the medium, it has been established that the coverage range for DSLAM is typically inversely proportional to the distance between the Central Office (CO) and the subscriber. The coverage range for the GPON technology is typically $20 \mathrm{Km}$. Further steps are being taken to extend the reach of GPON. Some of such include the use of optical amplifiers and electronic repeater technologies which has been suggested to extend the reach of GPON to $135 \mathrm{~km}$ [15]. This therefore makes the GPON technology a better option when considering fast-tracking broadband internet penetration in Nigeria.

\subsection{The Multiplexing Factor}

DSLAM (Digital Subscriber Line Access Multiplexer) is a multiplexing technology that is used for multiplexing several users onto a higher speed link. The technology allows reducing the number of physical connections between the Central Office modem equipment and the backbone and is usually based on a TDM (Time Division Multiplexing) scheme. GPON however uses the Wave Division Multiplexing technology to transmit data bi-directionally (upstream and downstream) over a single optical fiber. To separate the transmitting and receiving signals of different users over the same optical fiber, GPON uses the broadcast technology for downstream data transmission. The TDMA technology is however upstream data transmission.

\subsection{The Scalability/Split Ratio Factor}

From the business perspective, the goal of investors is to use a limited share of resources to achieve their aims. Passive Optical Networks help us to achieve this aim because it is designed to operate on a Point-to-Multipoint (P2MP) topology or architecture. Consequently, GPON is a more flexible technology that also provides optical split ratio 1:32 or 1:64. The implication of this is that each fiber can serve up to 32 or 64 subscribers hence new customers can be added easily and future bandwidth is almost limitless with fiber. It is also interesting to note that research has further birthed the possibility of having one fiber serve 128 subscribers. The deployment of this technology will undoubtedly help to fast track the penetration of broadband internet in Nigeria.

\subsection{Green Technology Factor}

GPON is a green alternative to traditional network technology due to its capability to save $60-70 \%$ of power consumption. Optical networks use some form of passive components, such as an optical star coupler or a static wavelength router at the remote node. The components are referred to as passive due to the fact that the field-deployed network elements do not need to be powered. This is because the network itself does not have any switching in it and does not need to be controlled. A developing nation like Nigeria still experiencing challenges in the power section will without doubt benefit from any solution that will enable it to optimize the generated power.

\section{FAST TRACKING BROADBAND ACCESS IN NIGERIA THROUGH GPON}

Nations like Japan, South Korea, Lithuania, Sweden and the Netherlands have continually maintained the lead in broadband internet penetration. This is because of their outstanding deployment of next-generation networks based on FTTH or advanced cable systems. 
Presently in Nigeria, mobile wireless technology is the primary access technology for broadband services. The growing introduction and wide acceptance by subscribers of mobile networks based on $2.5 \mathrm{G}$ and $3 \mathrm{G}$ as well as the introduction of smart phones and other smart mobile devices with seamless ability to connect to the internet has been responsible for the current growth in internet access and usage. Presently, the deployment of approximately 28,000 $(2 \mathrm{G}), 15,000(3 \mathrm{G})$ transceiver stations; 134 million phone subscription representing 96 per cent teledensity; over 74 million internet users representing 52 per cent of the population has only been able to achieve a and a six per cent broadband penetration [4]. As mobile network operators further intensify the rollout of $3 \mathrm{G}$ across the country, this trend is likely to increase.

However, it should be noted that every wireless access technology shares a medium which is the air interface. The spectrum on this air interface, which is a scarce resource is shared among all the customers in a cell with the effect that average bit rate per user is inversely proportional to the number of active users in the access domain. This is already being experienced as the air interface is becoming overloaded in some areas and there are already calls for increased spectral allocation. Furthermore, wireless technologies are distance dependent and deliver maximum throughput only when the user is adjacent to the transmitter. Latency on mobile broadband networks is typically two to three times higher on a 3G mobile network than on a DSL network, and it can be much higher on older second-generation $(2 \mathrm{G})$ and $2.5 \mathrm{G}$ networks. This latency negatively affects the end-user experience for mobile data services, and it can make real-time applications such as gaming and cloud-based services impractical to use [16].

\section{CONCLUSION}

As the deployment of $4 \mathrm{G}$ LTE and $5 \mathrm{G}$ become widespread, the speed and latency of wireless network technologies will continue to improve. However, the demands placed on these networks by consumers will also continue to increase as businesses and homes continue to embrace broadband services and its accompanying data-hungry applications. Far from being competitors, however, high-capacity wireless and fiber networks will actively support each other as the need for GPON and other wired access technologies has become inevitable due to their inherent advantages. For enhanced penetration therefore, the best overall solution will have to combine several technologies with tradeoffs in elements such as costs, performance and coverage. Other factors like geography of the terrain and population density will also determine the economics of the technologies and the most suitable mix. All these will result in a most ideal solution for leapfrogging Nigeria to a high-speed broadband delivery.

\section{REFERENCES}

[1] Ogunfunmi Tokunbo, "Technology Convergence and the promise of Internet of Things: Prospects for Developing Economies", Covenant University Public Lecture Series, Vol. 4, No. 3, March 2015.

[2] The Federal Government of Nigeria, "Nigeria's National Broadband Plan 2013 -2018" (Available Online at http://www.researchictafrica.net/countries/nigeria/Nigeri a_National_Broadband_Plan_2013-2018.pdf)

[3] International Telecommunication Union Broadband Series, "Impact of Broadband on the Economy", A publication of the Telecommunication Development Sector, April, 2012 (Available Online at https://www.itu.int/ITU-D/treg/broadband/ITU-BB-

Reports_Impact-of-Broadband-on-the-Economy.pdf)

[4] Nigeria Communications Commission (2014), "2014 Year End Subscriber/Network Data Report for Telecommunication Operating Companies in Nigeria" (Available Online at http://www.ncc.gov.ng)

[5] Martin Courtney, "Whatever happened to Broadband over Power Line?", Engineering and Technology Magazine, Vol 8, Issue 10, October 2013 (Online at http://eandt.theiet.org/magazine/2013/10/broadbandover-power-line.cfm)

[6] Hassan Olumide, "Telecommunication Reforms and Effects of Competition on Availability, Quality and Cost of Service in Nigeria", International Institute for Science, Technology and Education (IISTE), ISSN 2224-5731 Vol.1, No.3, 2011

[7] Ndukwe Ernest, "An Overview of the Nigerian Telecommunications Environment, Nigerian Communications Commission". (Online at http://www.ncc.gov.ng/archive/speeches_presentations/E VC's Presentation/NCC CEO Presentation on Overview of Nigerian Telecoms Industry.pdf)

[8] Global Industry Analysts, "Submarine Optical fiber cables: A global strategic business report" (2013).

[9] Global Internet Report 2014, "Open and Sustainable Access for All” (OInternet Society, Geneva, Switzerland (Available Online at www.internetsociety.org)

[10] http://www.terabitconsulting.com/downloads/2013submarine-cable-market-industry-report.pdf

[11] Kazovsky L.G, D. Gutierezm, N. Cheng, "NextGeneration Optical Access Networks", Journal of Light wave Technology, Vol.25, No 11, November 2007, pp $3428-3442$

[12] Amitabha Banerjee, "Wavelength Division Multiplexed Passive Optical Network (WDM-PON) technologies for broadband access", Journal of Optical Networking, Vol.4, No.11, November 2005.

[13] Nicholas John Lippis III, GPON vs Gigabit Ethernet in Campus Networking; A Lippis Consulting Industry Paper, February 2012.

[14] A report by The Broadband Comission, "The State of Broadband 2014: Broadband For All”, September 2014 (Available

Online: http://www.broadbandcommission.org/documents/report s/bb-annualreport2014.pdf)

[15] Shawbaki, Walid Suleiman, "Security enhancement in Passive Optical Networks through wavelength hopping and sequences cycling technique"(2006), Retrospective Theses and Dissertations Paper 1305

[16] A Cisco Systems white paper (2011), "Broadband Access in the $21^{\text {st }}$ Century: Applications, Services and Technologies" (Available Online at http://www.cisco.com/c/en/us/solutions/collateral/service -provider/service-provider-strategy/white_paper_c11690395.pdf) 